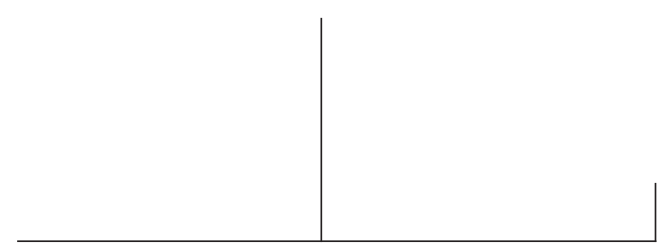

Rev. Latinoam. Psicop. Fund., II, 4, 81-93

\title{
O incesto e as ocorrências incestuosas: notas de referências
}

Aluisio Pereira de Menezes

O texto trata das significações do termo "incesto" no interesse da teoria e da clínica psicanalíticas. Procura situar uma certa diversidade de significações do que estaria em jogo, essencialmente, na conceituação e nas ocorrências incestuosas. Traz um mapeamento esquemático das idéias mais imediatas que balizam o entendimento das ocorrências incestuosas.

Palavras-chave: Incesto, psicanálise, abuso sexual, cultura 


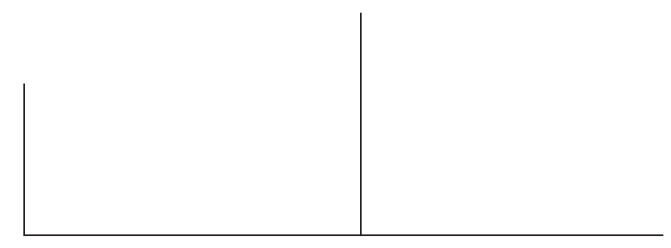

Este texto pretende indicar alguns pontos importantes relativos à questão do incesto. A questão do "incesto" traz significações que nem sempre são distinguidas. Nem sempre elas se encontram no mesmo plano. Cabe distingui-las em virtude do que aí se acha implicado. Como não é difícil perceber, há uma diversidade de saberes e de perspectivas que tratam do assunto. Saberes ligados à História, à Mitologia, à Religião, ao Direito, à Sociologia, à Antropologia, à Biologia, à Etologia, à Medicina, à Pediatria, à Psiquiatria, à Criminologia, às Artes, à Psicologia, à Jurisprudência, à Psicanálise. Mas o principal objetivo aqui é o de traçar um roteiro mínimo que afigure uma determinada apreensão, no essencial, de tudo que recebe o nome de incesto.

Em função da necessidade de aprofundar a formação de psicanalistas no trato dos problemas decorrentes do abuso sexual de crianças e adolescentes, sob forma incestuosa ou não, é que traçamos um quadro de referências que comece a instrumentalizálos para o desafio, por vezes extremo*. Mas ela terá serventia, sem a menor sombra de dúvida, para outros profissionais que estão tendo de haver-se com tais problemas nas atualidades urbanas. É certo que o alcance dessas referências extrapola seu emprego

* A minha experiência de referência comporta a observação semanal da sucessão de casos, durante o período de um pouco mais de dois anos (dezembro de 1996 - fevereiro de 1999), na Clínica da Violência, Rio de Janeiro. Além da observação dos casos e da interlocução, muitas vezes diária, sobre os seus desdobramentos com a Dra. Graça Pizá de Menezes (que foi quem criou e dirige a Clínica da Violência), além do acompanhamento de pais às voltas com essas situações dolorosas, organizei um primeiro conjunto de balizas teórico-clínicas que viesse a dar respaldo e coerência ao trabalho psicanalítico ali posto em prática. O presente texto reflete, de forma bem resumida e sintética, sobre um certo núcleo mínimo de questões introdutórias para quem, de dentro da psicanálise, tenha de se haver com essa ordem de dificuldades e suas conseqüências. 


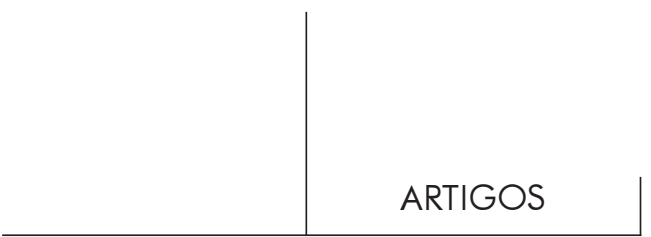

imediato, já que a magnitude e, sobretudo, a visibilidade da violência com crianças e adolescentes nos obrigam a repensar sobre que bases os mecanismos identificatórios estão assentados na cultura concreta em que vivemos e quais são suas consequiências para a vida social em geral, no nosso futuro próximo.

Apresentamos, assim, um roteiro de referências que sirva para nortear e ajudar a lidar com as intrincadas situações provocadas particularmente pelo abuso sexual incestuoso. São elas as ocorrências incestuosas. São situações envolvendo a família ou as famílias e, no mínimo, algum nível institucional da sociedade.

O problema é bem mais amplo. Ele diz respeito, portanto, aos danos causados nos mecanismos identificatórios da criança e do adolescente. É preciso que se enfatize bastante isso. Não temos ainda como saber se a extensão do que ocorre hoje existe, comparativamente a outros momentos da sociedade brasileira (e mesmo de outras sociedades), num volume de casos que colocaria a atualidade desta passagem de milênio num patamar inédito. Exibe-se o problema como nunca. Multiplicam-se os relatos. Pode-se mesmo dizer que há até um certo gosto nisso. Que o uso sexual de crianças e adolescentes, fora ou até dentro de um contorno incestuoso, tenha se tornado uma mercadoria é algo hoje evidente. Setores e instituições, governamentais ou não, são criados para enfrentar o conjunto desses problemas. Mas, numa tal circunstância, especificamente, em que medida o volume de ocorrências incestuosas não obedeceria a uma curva quase estável se considerarmos (admitindo-se termos dados precisos) uma escala temporal, digamos, do século XIX para cá, guardadas, é claro, as proporções demográficas de cada momento para o qual se olhe? O fenônemo da banalização do incesto, apesar de tudo, precisa ser considerado e avaliado com cuidado. Começa também a ficar remota a época em que o ato incestuoso era objeto de efetivo horror. Saberemos o significado disso? Quais serão as implicações?

Por ora, enquanto não se têm dados realmente precisos sobre a extensão, procuramos armar uma inteligência e uma sensibilidade que venha cada vez mais dimensionar o tratamento psicanalítico para tais circunstâncias. Mas, mesmo tendo ainda a justa medida do que acontece (a aparência trazida pela mídia não serve de referencial), o número de casos que, no período de dois anos, chegou à Clínica da Violência, é suficiente para que, além de estabelecer o acolhimento e o tratamento das vítimas e de seus familiares, se perceba ser necessário uma ação informativa e preventiva. Nesse sentido, evitando qualquer dimensão técnica ou erudita, procuramos trazer indicações que sirvam tanto para refletir a especificidade dessa clínica quanto para construir uma política de informações capazes de modificar o entendimento quase sempre extremamente canhestro dos profissionais envolvidos (a saber: professores, assistentes sociais, conselheiros tutelares, médicos, pediatras, psiquiatras, advogados, psicólogos, promotores, juízes, desembargadores, juristas, e mesmo os psicanalistas). 


\section{A filiação e a proibição do incesto}

A proibição do incesto é o nome de uma noção charneira para se conseguir distinguir o que qualificaria irredutivelmente o que é próprio da espécie humana e o que não é. A rigor, tudo aquilo que, aos olhos dos homens, pode parecer similar ao que se reconhece como proibição do incesto em relação aos animais deve ser considerado uma maneira aproximada de falar. Se a proibição do incesto for vista como uma instituição, como um operador que ordena lugares e posições ao mesmo tempo que estabelece um horizonte de valores servindo para legitimá-los no processo de manutenção da vida numa coletividade que queiramos humana, é certo que nada indica que "incesto" ou "proibição do incesto" possam designar processos presentes nas demais espécies vivas. Aquilo que entre os animais foi chamado de "incestuoso" ou como decorrente da presença da sua interdição é apenas uma maneira bem imprecisa de falar. Quando relações sexuais entre animais não-humanos consangüíneos existem, ou quando são inibidas, em nenhum momento podemos falar de "incesto". Os estudos revelam a presença, ou não, de mecanismos que funcionam como freios. Certas espécies espontaneamente inibem a facilitação sexual que a proximidade provoca. Outras não. E só.

Abandonando, então, a perspectiva antropomórfica que, no interior dos diversos saberes compuseram as tradições culturais de entendimento, fez pensar realidades diferentes por meio do mesmo termo, trazendo com isso muitos mal-entendidos, entre os quais a discussão a respeito da universalidade da "proibição do incesto" baseada no fato de que até mesmo entre os animais poderia ser verificada, vamos perceber que o que pode garantir a suposta universalidade - se universalidade há aí - não é porque o Criador colocou este expediente de ordenação incrustado na lógica coletiva dos seres comandados pela reprodução sexuada. Os estudos mostrando que, entre determinadas espécies, a prática "incestuosa" é trivializada em nada modificam a confusão. A admitida universalidade não será mais ou menos aceitável porque se verifique ou não, entre os animais, práticas que se parecem com aquilo que caiba no termo "incesto". O que importa é buscar o entendimento preciso do que significa a "proibição do incesto" para as sociedades humanas. Trata-se de poder conceber com clareza a importância da visão pré-histórica e histórica da questão. Tudo indica que teremos de considerar que, se universalidade houver, repetimos, ela precisará ser contraposta ao fato de que não há traço desse instituto antes do paleolítico superior. O que nos coloca diante de um "universal" inventado num determinado tempo. Será obra de Deus? Seria obra de Deus por intermédio do Homem? Ou seria puramente obra do Homem?

Tudo isso nos mostra que a questão do incesto é extremamente profunda. Ela situaria uma fronteira a partir da qual se pode considerar a especificidade do humano. Ela traz no seu bojo a forma de articular a diferença entre o que se com- 


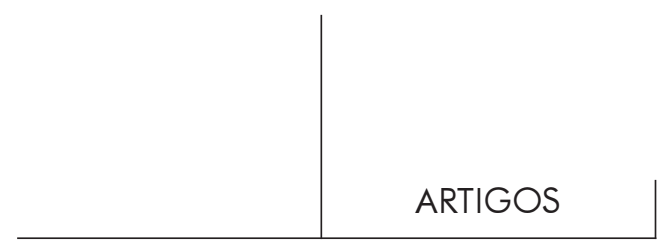

preende como sociedade animal e como sociedade humana. Se considerarmos na totalidade a presença desse instituto, de dentro da Cultura que organiza o sentido das sociedades construídas pela espécie humana, iremos ver que existem configurações, em espaço e tempo determinados, em que o incesto, a prática incestuosa concreta, é regra na reprodução da linhagem do poder. Algumas monarquias históricas, determinadas organizações matriarcais e certas situações provocadas por guerra ou por flagelos dizimadores, ou mesmo certas opções práticas de manutenção de patrimônio mostram que a efetiva prática do incesto teve lugar. Ou seja, casamentos entre pais e filhas, entre mães e filhos ou entre irmãos. Contudo, é preciso estar atento a que essas ocorrências estão ligadas a uma tradição e à observância de seus ritos, ou então aparecem na urgência da sobrevivência da comunidade em função de decisões motivadas por um realismo político no qual, de algum modo, os atos são coletivizados. Não estamos nos referindo às incestuosidades decorrentes do isolamento familiar do meio rural, nem à "tradição" dos atos incestuosos, sonhados ou realizados, no interior das famílias de conformação citadina ocidental.

Uma coisa é o nome de um instituto que situa a função da proibição como organizadora de uma lógica geral da troca e, portanto, de organização e reprodução social humana. A ênfase aí não está na modalidade do princípio de sucessão paterno ou materno. Outra, bem diferente, é o incesto designar de uma conformação de parentesco denominada patrilinear e pretender tomá-la como uma categoria universal. $\mathrm{O}$ que seria demonstrar um desconhecimento do que sejam as estruturações matrilineares em que não se verifica nenhuma alergia ao incestuoso entendido como reconhecimento dos frutos da relação sexual entre próximos, consangüíneos ou não. Outra ainda seria tomar o termo incesto para se referir ao conjunto de intenções ou de passagens ao ato, em função de diversas causas, que podem comparecer no seio da proximidade familiar ocidental, entre seus membros, principalmente entre pai e filha ou entre pai e filho, e mais raramente entre mãe e filho ou filha.

Disso se extrai, por um lado, que não há nenhum sentimento intrínseco à espécie humana, pensada assim na sua generalidade, que indique um espontâneo recuo diante do incesto. Não há nenhum terror intrapsíquico inato. O horror ao incesto é uma construção cuja economia sempre visou estabelecer um modo de ordenação na forma de aparecimento dos seres procriados. A enorme maioria das sociedades sempre teve na proibição do incesto o seu instrumento pivô. Pelo aspecto quantitativo, não resta a menor dúvida de que a proibição do incesto ocuparia a quase totalidade das disposições criadas para assegurar um princípio que desse lugar e legitimação aos produtos da reprodução sexuada humana.

Pertencer à Cultura passa necessariamente pelo aprendizado de uma pedagogia cujo resultado final será o de criar o sentimento de horror diante das relações incestuosas. Excetuando, então, as situações anteriormente aludidas, o que temos é que a quase totalidade das culturas, de algum modo, se organizou por meio de 


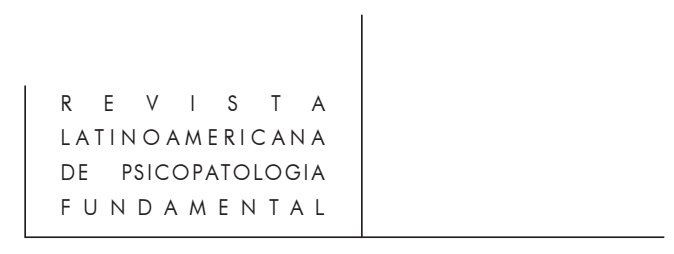

uma pedagogia na qual a relação sexual com determinados próximos fosse devidamente condenada em função dos processos da economia social. O rosto da família ocidental se enquadra nessa lógica. Não importa se os motivos disseminados do porque da proibição sejam verídicos à luz do que hoje podemos saber ou não. Não se irá defender o incesto porque se sabe agora, sobretudo nos espaços urbanos, que a progênie incestuosa não é geneticamente monstruosa ou traz em si "taras" ou "degenerescências". Muito do que se veicula na transmissão desse sentimento construído de horror constitui, pragmaticamente, um saber que se coaduna com as moralidades e as manutenções dos hábitos, tidos serem necessários para manter a unidade e a ordem de cada sociedade.

De outro lado, há um aspecto mais profundo nisso tudo que pode, a olhos rápidos, passar por um mero dogmatismo da reprodução social, ainda que necessário. A construção e a transmissão do sentimento de horror asseguram o estabelecimento de um princípio de ordenamento dos seres humanos. Isso é extremamente importante. É claro que se há "proibição", é porque há "desejo". A tendência incestuosa é uma manifestação desse "desejo". E ela teve de sofrer restrição. Veremos que a base biológica da inserção mamífera traz em si um componente indutor à incestuosidade. As construções culturais procuraram criar condições para suspender a espontaneidade sensível dos apegos e das manifestações impulsivas. $\mathrm{O}$ que os estudiosos acabaram percebendo é que esse processo elementar é o que delineia o caminho mínimo para que, por meio de uma negação no fluxo espontâneo do apego ou do impulso, se possa adquirir uma posição na escala das sucessões e um recurso de identificação com a separação diferenciadora. Ser filho de e de marca o acesso ao nível mínimo dos mecanismos identificatórios, mas também, em virtude da operação que se deve aí realizar, o acesso, em última instância, ao princípio de Razão, à ordem simbólica.

Nesse sentido, para além da dimensão objetiva da forma como as culturas constituem a pedagogia e a transmissão do que deve ser proibido, o que certamente mostra a grande diversidade de maneiras de regular os acessos aos processos simbólicos e às identificações, temos aí algo que é nuclear. É o aspecto geral da presença da proibição do incesto tanto em culturas em que o mito comanda o sentido da reprodução social quanto nas culturas que são mais distantes da determinação mítica. Isso a tal ponto que se quer pensar, pela designação "proibição do incesto", a condição constitutiva da espécie humana em toda a sua generalidade. É aí que se tem um conjunto bem amplo de maneiras de punir as infrações. É aí que se inicia a longa pedagogia do que pode e do que não pode como maneira de administrar as relações sexuais e suas consequiências no seio de diversas sociedades, mas não só. Estamos diante das bases pedagógicas em torno das quais as demais legiferações tomam corpo. Mas é por aí também que, segundo alguns, se começa a ter acesso às identificações mais desprovidas de conteúdo. 


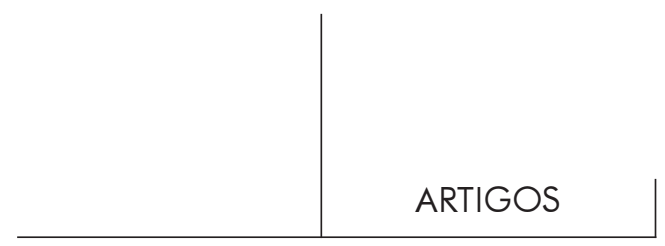

Devemos então considerar que o incesto designa a admissão de um operador que é, em última instância, o que vai permitir às sociedades se regularem em função de uma dominância semântica de base mítica ou não. O caráter restritivo desse operador pôde acarretar, por vezes, punições extremamente severas. A espontaneidade do impulso que leva ao incesto, em cada sociedade e no bojo de cada cultura, terá de enfrentar o regime de restrição do que as pedagogias procuraram transmitir. É evidente que, se tais impulsos tivessem se sobreposto continuamente, e se tais processos pedagógicos e respectivos regimes de controle e punição não tivessem conseguido estabelecer a dominância de um espaço de respeito ao que não se deve fazer, muito do que é nosso entendimento sobre o que é sociedade e cultura teriam outro formato, se é que a espécie humana houvesse sobrevivido, como muitos não temem em duvidar.

Certamente que a questão do incesto provoca toda uma consideração sobre o que é o específico da espécie humana. Ela motiva uma série de teorias a respeito do que funda o humano. É claro que nem todos os estudos giram em torno da defesa do caráter universal desse instituto. O importante é que, com uma tal preocupação ou não, se evidencia o nexo entre a interdição e os mecanismos identificatórios. É preciso ter clareza aí. Falamos de mecanismos identificatórios num sentido também geral. Nesse plano, o que se evidencia é a marcação de uma diferença ( ser filho de e de) e a admissão de uma cena na qual o princípio da nomeação implica necessariamente, para dizer de um modo sintético, um eixo de referência cuja consistência é a de colocar esse ser diante de uma determinação irredutível à origem da reprodução sexual de acordo com a gênese da ordem do vivo. A partir do nome, o ser humano está identificado como filho da linguagem. É esse o sentido profundo do Édipo no pensamento psicanalítico.

Essa questão de há muito foi pensada na tensão entre o que seria a carga derivada do fato de se ser um ente biológico (pertença identificatória da espécie) e o que decorre de o homem participar de um processo no qual o sentido do seu ser o remeta a um princípio que o filie à lógica do nome. Sim, "natureza" e "cultura". Mas é preciso observar que já na "natureza" existe o societário. Os processos de vinculação entre os seres são atualizáveis em função de determinações comandadas por processos e mecanismos que comparecem, em graus de complexidade crescente, dos insetos aos primatas e aos seres humanos. A "cultura" introduz no seio desses processos de vinculação outros processos de vinculação também em complexidade crescente e em aberto, se tomarmos como baliza os perímetros "identificatórios" restritos das outras espécies que a humana.

Os processos de vinculação que se realizam como cultura se traduzem em formas que contêm graus crescentes de abertura. A diversidade de culturas mostra bastante bem como cada cultura é ciosa dos seus processos de vinculação. É o que assegura a identidade dos que a realizam e a vivem. A diferença de modos e os 
graus de alteridade admitidos mostram que o princípio dogmático da filiação cumpre o papel central de resguardar a cultura e com isso a vida da própria sociedade. Os caminhos identificatórios postos em operação por cada sociedade vêm arrumar a base mínima com que outros planos podem ser expandidos.

Das estruturas elementares de parentesco às construções familiares ocidentais, e sem que sejamos obrigados a pensarmos nisso evolutivamente, o que temos é a inarredável presença de um sentimento de horror ao incesto. Contudo, apesar das diversas crises por que passou a Cultura Ocidental, nunca se viveu na progressiva banalização desse horror. $\mathrm{O}$ incesto sempre foi perpetrado. Não faltam documentos a respeito. Seja nas sociedades mais restritivas, seja nas de movência mais "permissiva". O que talvez seja novo como manifestação é a sua banalização. O que nos cabe levar em consideração e pensar com toda a atenção é em que medida o esgarçamento progressivo desses processos de vinculação graças às modificações na cultura atual vem interferindo de fato na tradicionalidade do que se compôs como princípio de filiação? Terá isso como conseqüência uma maior amplitude da violência generalizada?

Dentro de todo esse quadro é que podemos situar um aspecto que qualifica a atualidade. Tocamos aí no âmbito das famílias urbanas. O fenômeno da banalização nos remete a uma realidade na qual o incesto é extremamente precoce. Bebês são abusados. Há registros de que o abuso sexual, incestuoso ou não, se dá desde o primeiro ano de vida. O que se soube de casos de abuso sexual incestuoso no século passado, em que os autores faziam parte daquele galeria tipológica estudada pela psiquiatria, revela que os abusadores hoje podem ser homens (na enorme maioria dos casos são homens) de toda extração, de toda e qualquer formação cultural, de todo e qualquer segmento social.

É um novo contexto que se configura. Nele não vale mais o peso inibidor da pedagogia que transmitia o horror. Esses abusos podem se dar do extremo de se terem como atos de amor ao outro extremo, de fria realização, sem a menor empatia pela vítima, mesmo quando é um filho, ainda que o discurso diga o contrário, quando a situação vem à tona e o leva a ser inquirido. $\mathrm{O}$ que se banaliza não é apenas a forma de incestuosidade com adolescentes. Há uma grande literatura a respeito. $\mathrm{O}$ que vem se trivializando é o abuso com bebês e crianças na primeira infância. Incesto, nesse novo contexto, significa um ato que, no plano das sociedades ocidentais, continua ferindo sim um princípio de filiação relativamente vigente nas sociedades urbanas, mas, dada a idade das vítimas, um ato que pode simplesmente impedir o curso já difícil de estruturação de uma criança numa sociedade progressivamente mais entregue a um regime de consumo imediato de tudo. É aí, nesse momento, uma violência psíquica que pode conduzir à desestruturação psicótica ou mesmo à desestabilização neuro-endocrinológica grave (por vezes capazes de levar à morte) pelo estresse a que são submetidos bebês ou crianças. 


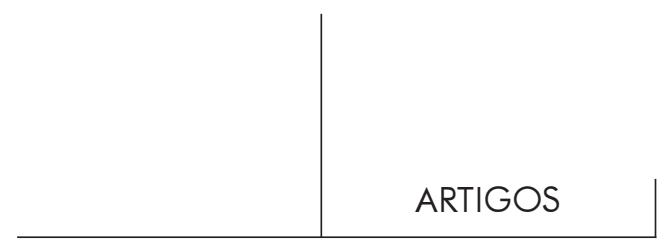

Fixações incestuosas

Além das acepções indicadas, existem outras que tocam a dimensão da organização psíquica. Existe um sentido do que será o "psíquico" relacionado ao termo "incesto". Há aí um sentido que mistura o metafórico e o concreto dos próximos familiares.

Antes de mais nada, devemos levar em conta que a espécie humana, em virtude de sua prematuração biológica, fica longamente exposta à proximidade daqueles que são seus pais, e particularmente da mãe, seja ela a biológica ou não. O fato mamífero com certeza prepondera. A sexualidade humana paga seu tributo às determinações da função vital, embora jamais se possa concebê-la como uma pura extensão da sexualidade decorrente do que se conceba na qualidade do que é de natureza biológica. Se considerarmos que o funcionamento do cérebro e todas as funções de que é capaz tornam fortemente substantivas a significação do termo "psíquico" que delas deriva, veremos que existe ainda um sentido de "psíquico" para o qual, a rigor, fomos preparados pela psicanálise. É dentro desse enquadramento que cabe dizer que existe um entendimento de "psíquico" relacionado com a noção de "incesto", tanto recobrindo a questão da filiação quanto designando uma forma de apego a objetos (externos, internos, parciais, totais) que estarão sob o signo da proibição ou mesmo da impossibilidade, concreta ou metaforicamente girando em torno da "mãe" como o objeto ou traço do que é querido e requerido como forma de satisfação ou gozo. Para designar as formas fortes desse apego falamos de fixações.

Quais seriam, então, os pontos de fixação a que um ser pode ficar submetido no seu destino de maneira patológica, dada sua condição? Etólogos, pediatras e psicólogos desenvolvem estudos e teorias nos quais buscam dizer a partir de que momento, na constituição de um ser humano, a estruturação de vivências será determinante, patologicamente ou não. Muitas observações, embora relativamente controversas, apontam para o peso que tomaria a vida fetal como centro de fixações a que poderia ficar assujeitada uma criança, por trás de uma sucessão de acontecimentos negativos que a isso se sobreporiam (os maus tratos, os malentendidos, os diversos graus da violência, seja ela sexual ou não, incestuosa ou não), a ponto de prejudicar ou até imobilizar os mecanismos das identificações que a constituirá, sobretudo nas modalidades culturais em que as margens de escolha sejam mais abertas e mutantes, como é o caso de nossa cultura, se comparada aos regimes identificatórios mais exclusivos das culturas nas quais um cinturão mítico as organiza.

Tanto para o entendimento dos caminhos comuns que estruturam a vida de uma pessoa, quanto para o que a desestabiliza, a contribuição da psicanálise foi 


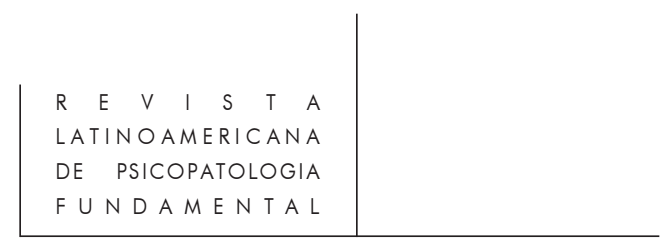

enorme na provocação e no aprofundamento dessas questões. Ela trouxe à luz todo esse conjunto de elaborações e de condições de trato com a escuta e a palavra que possibilitaria a percepção desses lugares dificilmente redutíveis às fases de um desenvolvimento psíquico baseado numa medida, em última instância, biológica. As fixações de que ela trata dizem respeito a elementos que tensionam o psiquismo do ser humano no vetor do prazer e do desprazer, no vetor das ambivalências afetivas e, com isso, no vetor dos mecanismos que darão condições àquele ser sensível de tornar-se alguém na sociedade.

No sentido metafórico e geral, pode, portanto, ser chamado de incestuosa toda fixação que se estabeleça dentro de uma situação em que o corpo da mãe nuclearize para o psiquismo um eixo em torno do qual ele irá se desenvolver ou paralisar a movimentação erótica e seus diversos aspectos identificatórios. Sendo assim, até a dimensão da vivência fetal pode eventualmente estar em jogo na determinação de sofrimentos graves. Como isso envolve o corpo da mãe, o uso metafórico de fixações incestuosas tem justificativa desde este nível. Mesmo desconsiderando todo e qualquer valor da dimensão fetal, teremos ainda assim a intensificada relação da mãe com o bebê como um tempo e um espaço no qual se jogará uma multiplicidade de cenas que poderá ter como resultante fixações da criança a elementos internos à vivência do bebê com aquele ser que desempenha a função de mãe. E é no interior da vida de relação com os outros, inicialmente, os próximos familiares, que irá se tecer apegos que poderão tornar-se problemáticos, ou mesmo suceder situações invasivas do corpo do bebê ou da criança que poderão desembocar em situações que recobrem as significações ligadas às regras de parentesco, ali justo onde a constituição do eu e seus objetos deve fazer face à externalidade das marcações separativas da filiação.

Mas o que faz esses três níveis terem o caráter propriamente problemático? Que acontecimentos levariam a vivência física com o corpo da mãe - a inarredável vinculação mamífera - a fixações psíquicas que denominaríamos de incestuosas? Outros recusam ou diminuem a força de tal determinação. Pensam que o decisivo para a vivência psíquica e, portanto, para aquilo que poderia ter um sentido problemático de fixação ao corpo e ao psiquismo da mãe, o que estabeleceria uma acepção do incestuoso, dimensionando o forte apego ao matricial, proviria da relação mãe-bebê e ao mundo inicial que cerca o bebê ou a criança, do que aí se passa. De qualquer modo, para além dessa relação, e se cruzando com ela, e mesmo além de toda a marcação separativa advinda da proibição incestuosa, não se pode minimizar a força dos acontecimentos traumáticos, e, em particular, os decorrentes da invasão corporal da criança.

Uma série de comportamentos aí são específicos em função desse objeto privilegiado. Esses comportamentos atualizam maneiras próprias ao modo humano 


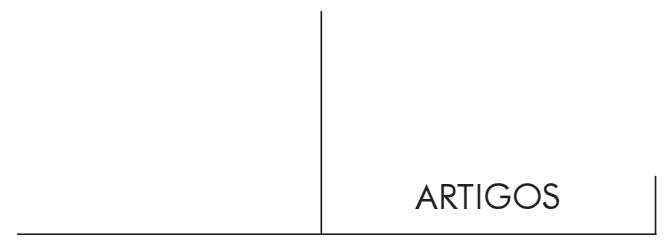

de ficar conectado a esse ser que cuida. São vínculos de apego extremamente importantes na estruturação do eu da criança. Mas assim como são espontâneos nas suas manifestações e mesmo na sua necessidade (sabemos, quantitativamente pelo menos, dos problemas que a falta de presença sistemática dos que cuidam e operam o tocar e o apego aos bebês pode provocar), esses mesmos comportamentos ligados à proximidade precisam, aos poucos, sofrer a intervenção separativa de modo a que aquele ser possa vir a constituir-se.

Tem-se aí uma primeira significação geral do termo "incesto" ligado à dimensão psicológica. Os processos de formação de um ser visam justamente deslocá-lo do apego necessário ao objeto privilegiado a fim de que novos objetos diferenciados se coloquem. É toda complexidade da vida relacional que se inicia. Um autor procurou designá-la por meio da expressão "biologia periférica". É em relação a isso que se pode situar a importância do que a psicanálise trouxe com o complexo de Édipo e com o pré-edípico. Há uma zona de intercessão entre o que é a matriz dos apegos aos primeiros objetos no limite do etológico e a dimensão separativa que procura quebrar a tendência espontânea de fixar-se ao que decorre da contingência da prolongada prematuração dos indivíduos da espécie humana. De forma muito sintética, pode-se dizer, pois, que existe uma tendência irredutivelmente incestuosa no psiquismo no sentido em que esses apegos, de uma maneira ou de outra, mesmo depois da ação separativa, exercem uma força de atração poderosa. Isso no sentido geral, já que não estamos nos referindo a nenhuma história em particular, e estamos desconsiderando a força impositiva dos processos separativos e o impacto das situações traumáticas que, em graus, acabam, na diversidade das culturas, integrando esse ser em formação num campo de objetos coletivos. É evidente que, dependendo da forma como cada cultura se organiza, a história pessoal terá maior ou menor relevo.

No entanto, dentro da progressiva psicologização das sociedades ocidentais, o passado dos acontecimentos que vão do mutismo do bebê às vicissitudes das situações que irão envolver a criança pesa como referência estruturadora maior. É por isso que o abuso sexual incestuoso coloca um problema que agrava a já difícil tarefa de todo ser em sua luta por constituir-se e tornar-se independente por meio do que se abre como possível em nossas sociedades não marcadas por identificações convergentes comandadas basicamente pelo regime mítico.

Dessa maneira, enfim, pelo menos duas acepções se delineiam. A primeira, geral, para designar toda forma de fixação que o ser humano traz relativa aos seus primeiros objetos de apego, num plano etológico, cujo horizonte é, na verdade, biológico em última instância, muito embora isso assuma uma consistência biocultural. A segunda nos coloca diante daquilo que decorreria de acontecimentos que sobrevêm a esse ser, os quais poderão, em função da sua compleição biológica e do caráter do conjunto de ações de interação a que foi estando exposto, marcá- 


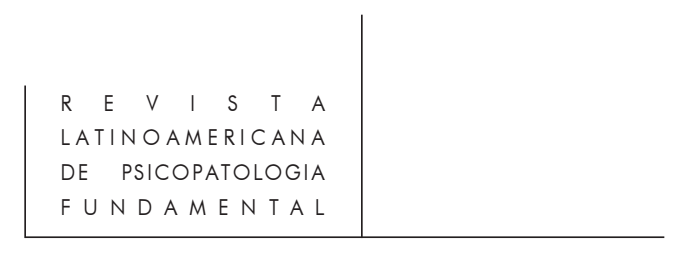

lo, mantendo-o fixado seja ao que remete ao fundo dos processos bioculturais, seja ao que lhe vem pela própria força dos encontros e dos desencontros diante dos impulsos que movem suas fantasias. É aí que a psicanálise trouxe um entendimento dos caminhos por onde a sexualidade humana se realizaria tanto numa sociedade que, aos poucos, foi tendo de lidar com a diversidade de manifestações sexuais, quanto naquelas em que a sexualidade obedecia a balizamentos mais estritos e guiados pelo mítico-religioso.

É com essa referência que se pode articular a noção de incesto com as fixações múltiplas das fantasias sexuais em torno dos objetos que criam o espaço-tempo das tensões psíquicas, quer no sentido do que provoca os passos criativos quer do que quebra e impossibilita o viver. Emprega-se aqui o termo incesto, nesta segunda acepção, abrangendo modulações que podem caracterizar toda sorte de marcas em torno das quais os processos psíquicos podem ficar comprometidos. O estudo da natureza e dos efeitos dessas marcas, a partir da nucleação "materna" e do entendimento do que se passa na relação constitutiva mãe-bebê, bem como de tudo o que se relaciona ao mundo concreto da família, mostra como elas exercem peso determinante nos mecanismos de identificação do humano. Tudo isso pode permitir que se admita o uso metafórico do termo "incestuoso" como uma maneira de designar a ordem de apegos constitutivos, eletivos ou mesmo traumáticos. Contudo, é preciso ter claro que a psicanálise trouxe ainda à consideração uma ordem de "apego" que não poderia se enquadrar nas indicações já feitas. Trata-se de algo difícil de colocar dentro da referência do prazer e do desprazer, mas que tem a força de ser como que nucleador do próprio psiquismo e tem sempre o caráter irredutível e insidioso.

$\mathrm{Na}$ realidade, para considerarmos os efeitos das relações incestuosas, no interior das configurações familiares dos centros urbanos ocidentais, sobre a formação das crianças e dos adolescentes no estado atual dessas sociedades será preciso ter claro o seu progressivo individualismo. Uma maneira de perceber isso está na fragilidade do sentimento de horror em relação ao incesto. Cada vez mais bebês e crianças da primeira infância são abusados, dentro ou fora da família. O fenômeno de intensificação da sexualização na cultura publicitária mercantilizou as imagens de adolescentes, de crianças e de bebês. Certamente ele deve ter contribuído em muito para a aceitabilidade da objetualização da sexualidade das adolescentes (particularmente as "ninfetas") e das crianças a partir de dois anos. Sendo assim, a consciência desses novos objetos sexuais, sobretudo nas últimas duas décadas, é um fator facilitador a que se tome, diretamente em casa ou não, a atração incentivada e construída por um dos aspectos da própria cultura do marketing. Há uma facilitação, no imaginário das culturas sob a égide dos meios de comunicação de massa, que, aliado a outros fatores, criou o enorme foco da erotização das crianças de primeira infância, das crianças mais velhas e dos adolescentes. Esse dado não 


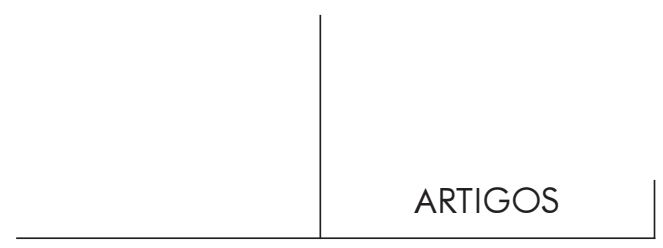

estava presente em Viena no fím do século passado nem há trinta anos. O que se tem por considerar hoje é como isso que, direta ou metaforicamente, pôde ser designado como incestuoso no pensamento analítico se torna, a olhos vistos, um procedimento cada vez mais trivial nas sociedades urbanas. Que efeitos terá no futuro próximo?

\section{Resumos}

Este texto trata de las significaciones del término "incesto" en el interés de la teoría y de la clínica psicoanaliticas. Busca situar una cierta diversidad de significaciones del que estaría en juego, esencialmente, en la conceptuación y en las ocurrencias incestuosas. Trae un plan esquematico de las ideas más inmediatas que balizan el entendimiento de las ocurrencias incestuosas.

Palabras llave: Incesto, psicoanálisis, abuso sexual, cultura

Il s'agit dans ce texte de las significations du terme "inceste" sur l'intérêt de la théorie et de la clinique psychanalitiques. Cherche situer une certain diversité de significations au qu'est en jeu, essentiellement, dans la conceptuation et dans l'occurences incestueuses. Faire un plane schématique des l'idées qui balisent l'entendement des l'occurences incestueses.

Mots cles: Inceste, psychanalyse, abus sexuel, culture

This text deals with the term "incest" regarding the theory and practice of psychoanalysis. It tries to establish the range of the various meanings that play a part in the incestuous occurrences and conceptualization. It brings a scheme of the immediate ideas that sustain the comprehension about the incestuous bearings.

Key words: Incest, psychanalyse, sexual abuse, culture 